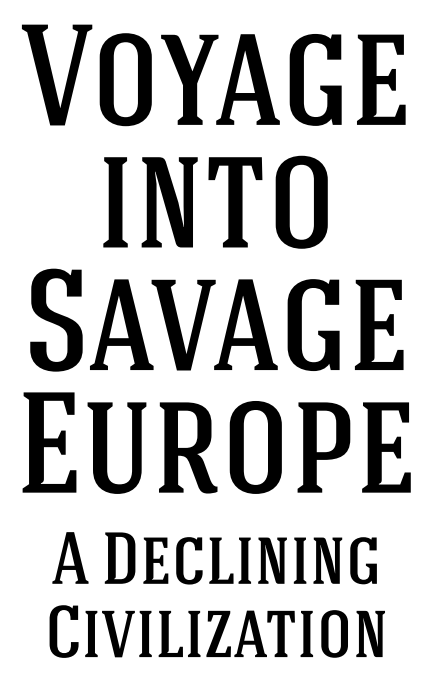





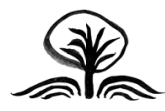

\title{
AVIGDOR HAMEIRI
}

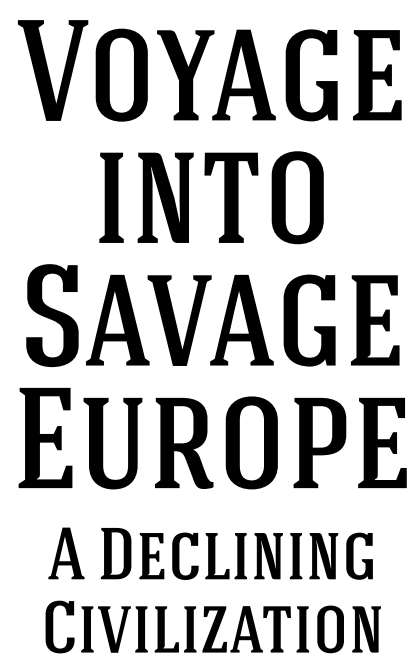

\author{
TRANSLATED \\ AND EDITED \\ BY PETER \\ C. APPELBAUM
}

$$
\begin{gathered}
\text { BOSTON } \\
2020
\end{gathered}
$$




\section{Library of Congress Cataloging-in-Publication Data}

Names: Hameiri, Avigdor, 1890-1970, author. | Appelbaum, Peter C., translator, editor.

Title: Voyage into savage Europe : a declining civilization / Avigdor Hameiri ; translated and edited by Peter C. Appelbaum.

Other titles: Masa' be-Eropah ha-pera'it. English

Description: [Brookline, MA] : [Academic Studies Press], [2020] | Originally published in 1938 as "Masa Be'eropa Haperait. Rishmei Derech Anakroniyim" (Journey to Savage Europe. Anachronistic Travel Notes).

Identifiers: LCCN 2020009946 (print) | LCCN 2020009947 (ebook) | ISBN 9781644693360 (hardback) | ISBN 9781644693377 (paperback) | ISBN 9781644693384 (adobe pdf)

Subjects: LCSH: Europe, Central--Description and travel. | Jews--Europe, Central. | Europe, Central--Politics and government--20th century.

Classification: LCC DAW1014 .H3613 2020 (print) | LCC DAW1014 (ebook) | DDC 943.703/2--dc23

LC record available at https://lccn.loc.gov/2020009946

LC ebook record available at https://lccn.loc.gov/2020009947

ISBN 9781644693360 (hardback)

ISBN 9781644693377 (paperback)

ISBN 9781644693384 (adobe pdf)

ISBN 9781644693391 (ePub)

Copyright, English translation (C) 2020 Academic Studies Press

All rights reserved.

Book design by Lapiz Digital Services.

Cover design by Ivan Grave.

On the cover: the cover of the original Hebrew edition of the book (Masa Be"eropa Haperait. Rishmei Derech Anakroniyim, 1938), courtesy of Yoni, Joel, and Gideon Shapira.

Published by Cherry Orchard Books, an imprint of Academic Studies Press 1577 Beacon Street Brookline, MA 02446, USA

press@academicstudiespress.com www.academicstudiespress.com 
For our murdered millions who didn't or couldn't heed the warning. 
